\title{
TERAPÊUTICA DA HANSENÍASE
}

\author{
LEPROSY THERAPEUTICS
}

Diltor Vladmir Araújo Opromolla

Diretor da Divisão de Pesquisa e Ensino do Instituto "Lauro de Souza Lima"- Bauru - SP

CorRespondênCIA: Hospital Lauro de Souza Lima - Caixa Postal 62 - Rodovia Comandante João Ribeiro de Barros - Km 225/226; Bauru/SP - CEP: 17001-970 - Tel. 0142-3022-44, Tel./Fax - 0142-3047-47

OPROMOLLA DVA. Terapêutica da hanseníase. Medicina, Ribeirão Preto, 30: 345-350, jul./set. 1997.

RESUMO: Nesta revisão, são discutidos os efeitos adversos dos quimioterápicos utilizados na terapêutica da hanseníase, a evolução das lesões submetidas ao tratamento específico, os esquemas mono e poliquimioterápicos, as reações imunológicas, provocadas pela terapia e, finalmente, as perspectivas de utilização de novas drogas e de vacinas contra a hanseníase.

UNITERMOS: Hanseníase. Quimioterapia Combinada. Terapêutica.

\section{INTRODUÇÃ̃O}

Durante muitos anos, o único tratamento contra a hanseníase foi o óleo de "chalmoogra", cuja origem se perde nos domínios da lenda ${ }^{1}$. Sua ação, contudo, era muito discutível, pois os casos em que aparentava ter alguma atividade eram casos que costumam regredir espontaneamente.

No início da década de quarenta, nos Estados Unidos, Faget experimentou uma Sulfona, o "Promin", no tratamento da hanseníase, com bons resultados. Outras Sulfonas, também ativas, apareceram e todas derivadas de um composto "mãe", a Diamino-Difenilsulfona $^{2}$. Contudo, verificou-se, mais tarde, que quem atuava mesmo contra a doença era esse composto "mãe", porque todas as drogas que o compunham acabavam se transformando no organismo.

Depois da Sulfona, outros medicamentos foram aparecendo com atividade anti-hansênica, tanto quimioterápicos como antibióticos, mas dentre todos eles, os que são considerados, hoje, como de primeira linha são a Sulfona, a Clofazimina e a Rifampicina.

\section{EFEITOS ADVERSOS}

A Sulfona, ou como é conhecida hoje, a Dapsona, é administrada na dose de $100 \mathrm{mg}$ por dia, sem períodos de repouso; a Clofazimina também é administrada nesta dosagem e a dose diária de $\mathrm{Ri}$ fampicina corresponde a $600 \mathrm{mg}$.

Todas elas são capazes de produzir efeitos colaterais (Tabela I). A Dapsona pode causar problemas digestivos, mas um dos mais frequientes é a anemia hemolítica que, na maior parte das vezes, não é muito grave, a não ser quando o indivíduo tem uma deficiência da Glicose-6-fosfato de desidrogenase. Também pode provocar Metahemoglobinemia, ficando o paciente com as extremidades, como os lábios e a polpa dos dedos, cianóticas. Outras manifestações, menos comuns, são hepatites tóxicas, reações cutâneas por fotossensibilidade, psicoses, e uma síndrome que ficou conhecida como a "Síndrome da Sulfona" ("rash" cutâneo, aumento de linfonodos, Icterícia, Hepatoesplenomegalia e Linfocitose com linfócitos atípicos) ${ }^{3}$. A Clofazimina também produz efeitos colaterais. Ela 
é um corante e causa uma pigmentação escura na pele, que se acentua com o sol, deixando, também, a pele mais seca, com aspecto ictiósico, e mais sujeita a eczematizações. Ocasiona também alterações digestivas, que não são de grande monta, na dose de 100 mg/dia. Quando essas doses são aumentadas para $200 \mathrm{ou}$ $300 \mathrm{mg} / \mathrm{dia}$, com a finalidade de tratar reações de eritema nodoso hansênico (admite-se que a droga tenha efeito antiinflamatório), depois de um tempo prolongado, como de dois ou três meses, os efeitos adversos gastroenterológicos são mais freqüentes e, mais graves, devido ao depósito de cristais da droga na parede intestinal. Há até casos que simulam um quadro de abdômen agudo ${ }^{4}$.

\section{Tabela I - Efeitos adversos das drogas} anti-hansênicas

- Dapsona:

- Dispepsia

- Anemia hemolítica dependente de g6PD

- Metahemoglobinemia

- Hepatite tóxica

- Fotossensibilidade

- Psicose

- Síndrome da sulfona: rash cutâneo, bidenomegalia, icterícia, hepatoesplenomegalia, linfocitose atípica

- Clofazimina:

- Sintomas digestivos: de dipepsia leve até abdômen agudo

- Manifestações cutâneas; hiperpigmentação, ictiose, eczematização

- Rifampizina:

- Administração contínua: rash cutâneo, dispepsia, hepatite tóxica e trombocitopenia

- Administração intermitente: os anteriores mais "síndrome pseudo-gripal", anemia hemolítica, insuficiência respiratória, insuficiência renal e choque circulatório

A Rifampicina também causa efeitos colaterais, e eles são mais freqüentes e mais sérios, quando ela é administrada de maneira intermitente, isto é, uma ou duas vezes por semana ${ }^{5}$. Quando ela é administrada diariamente, pode ocorrer "rash" cutâneo", distúrbios digestivos, hepatite tóxica e trombocitopenia. Administrada intermitentemente, causa uma síndrome "pseudo-gripal", e, além de também poder originar hepatite e trombocitopenia, causa insuficiência respiratória, anemia hemolítica, choque, e insuficiência renal ou por nefrite intersticial ou necrose tubular aguda.

\section{RESPOSTA TERAPÊUTICA}

A Sulfona e a Clofazimina são drogas bacteriostáticas e a Rifampicina é bactericida ${ }^{6}$, mas, apesar disso, todas elas têm uma maneira mais ou menos semelhante de manifestar sua atividade. Deve-se salientar, contudo, que a Rifampicina, por ser uma droga muito ativa, tem por isto efeitos iniciais mais rápidos.

Na Hanseníase indeterminada, é difícil avaliar a ação dessas drogas porque, nessa forma clínica, há somente máculas ou áreas com distúrbios de sensibilidade e praticamente não se encontram bacilos. No caso da Sulfona, porém, desde o início, se verificou que, quando administrada em casos indeterminados, com Mitsuda negativo, jamais esses casos se transformavam no tipo virchoviano, que é o que acontece sem tratamento.

Nos casos tuberculóides, também é difícil avaliar o resultado da terapêutica com essas drogas, porque eles têm, muitas vezes, uma tendência à cura espontânea. Em várias ocasiões, não se tem certeza se o indivíduo está se curando sozinho ou se é o medicamento que está exercendo o seu efeito. Apesar disso, todos esses casos devem ser tratados, porque, nos casos tuberculóides, é muito grande o risco do comprometimento neural, o risco mais sério nessa doença. Nos casos tuberculóides reacionais, ocorre a mesma situação, mas as manifestações aparecem de maneira aguda e aí os corticoesteróides podem ter uma ação importante, fazendo com que as lesões regridam rapidamente. $\mathrm{O}$ tratamento específico, contudo, precisa ser continuado, e a suspensão precoce do corticoesteróide pode acarretar a volta das manifestações agudas, o que é um grande inconveniente, não havendo outra escolha, quando esses casos exibem comprometimento neural agudo.

É nos casos virchovianos e dimorfos avançados, porém, em que a doença progride continuamente, sem a mínima tendência a regressão espontânea, que se pode observar, realmente, o efeito das drogas anti-hansênicas.

A maneira de esse efeito se manifestar, como já foi referido, é mais ou menos a mesma, seja qual for a droga utilizada. De um modo esquemático, pode-se dizer que um dos primeiros sinais de melhora, que se observa durante o tratamento de um paciente 
virchoviano, é o desaparecimento das lesões mucosas. Sabe-se que os pacientes virchovianos apresentam, com frequiência, obstrução nasal e epistaxe que prejudicam muito sua respiração, e, além disso, podem exibir lesões na cavidade oral, na língua, palato mole e duro, nas gengivas, e também no laringe, causando rouquidão. Nestes casos, quando surgem reações tipo eritema nodoso, pode ocorrer obstrução da laringe, levando à necessidade de uma traqueostomia, o que era freqüiente na era pré-sulfônica. Com o tratamento, o paciente logo começa a respirar melhor, a dormir melhor, a rouquidão desaparece, e as lesões do palato regridem, deixando uma cicatriz bastante característica, estrelada.

Depois das lesões mucosas, que melhoram nas primeiras semanas de tratamento, as manifestações, que também desaparecem logo no início, são as ulcerações em hansenomas e infiltrações que cicatrizam rapidamente.

Em seguida, desaparecem as lesões mais recentes. Nos pacientes virchovianos, a evolução da doença é crônica e os nódulos e outras lesões vão aparecendo muito lentamente. Primeiro, aparecem alguns hansenomas, que permanecem sem alterações, durante algum tempo, depois aparecem outros e assim por diante. Após meses ou anos, há então lesões de várias idades, e aquelas de aparecimento mais recente, menores e menos infiltradas, são as que regridem, aparentemente, em primeiro lugar. Depois de um mês ou um mês e meio, essas lesões se tornam planas e pregueadas e, só depois disso, é que começa a se tornar evidente a melhora das demais lesões que o paciente apresenta. Essas melhoras se acentuam do sexto ao oitavo mês, e, depois de um ano, as lesões já regrediram, de maneira que importantes melhoras continuam ocorrendo, mas de modo menos evidente, nos meses seguintes, e um caso avançado de Hanseneníase virchoviana chega a ficar sem lesões e sem bacilos somente depois de três a cinco anos de tratamento.

Esse tempo tão longo é uma limitação muito grande à terapêutica da Hanseníase, e muitos pacientes, depois de um período inicial, durante o qual obtêm alguma melhora, passam a ingerir o medicamento de maneira irregular ou o interrompem de vez. Outros problemas são a ocorrência freqüente de recidivas após a cura clínica, quando se faz o tratamento monoterápico e, às vezes, a piora da doença, após um período em que as lesões já melhoraram consideravelmente, evidenciando o aparecimento de resistência dos bacilos à droga ${ }^{7}$.

\section{ASSOCIAÇÕES MEDICAMENTOSAS}

Desde o início do emprego da Sulfona, já se considerava a possibilidade de resistência e isso foi comprovado, experimentalmente, por Pettit \& Rees ${ }^{8}$ em 1964, utilizando a técnica de Sheparda, a da inoculação de bacilos no coxim plantar de camundongos. Esse fenômeno foi se agravando, progressivamente, e, no fim da década de 70, muitos países apresentavam taxas alarmantes de resistência secundária à Sulfona. Posteriormente, com a demonstração de resistência inicial também, isto é, contaminação de indivíduos com bacilos já resistentes, intensificou-se o temor da perda de um dos medicamentos mais importantes no tratamento da Hanseníase. E, se não bastasse isso, também foi demonstrado, experimentalmente, a resistência secundária à Rifampicina 9 .

Consciente disto, a Organização Mundial da Saúde (OMS) propôs, em $1977^{10}$ a associação de medicamentos para o tratamento da doença. O Brasil foi um dos únicos países a seguir essa recomendação, adotando, para o tratamento dos casos dimorfos e virchovianos, a Sulfona mais a Rifampicina, esta, administrada durante os três meses iniciais e aquela, até a cura clínica. Quando se suspeitava de resistência à Sulfona, ela era substituída pela Clofazimina.

Apesar disso, a maioria dos países continuou a fazer uso da monoterapia com Sulfona, ou por questões econômicas ou por falta de compromisso com o problema da doença. Foi aí que a Organização Mundial da Saúde, em uma recomendação mais enfática, propôs esquemas terapêuticos que utilizavam as drogas consideradas de primeira linha para o tratamento da hanseníase ${ }^{11}$.

A princípio, a OMS dividiu os pacientes em paucibacilares $(\mathrm{PB})$, que compreendiam os indeterminados e tuberculóides, e multibacilares (MB) que seriam os dimorfos e virchovianos. Os PB seriam tratados com Sulfona (Dapsona) $100 \mathrm{mg} / \mathrm{dia}$, sem supervisão, e Rifampicina, $600 \mathrm{mg}$, uma vez por mês, em doses supervisionadas, durante seis meses. Os multibacilares (MB) receberiam Sulfona, 100mg/dia, mais Clofazimina, 50mg/dia, sem supervisão, e $600 \mathrm{mg}$ de Rifampicina e 300mg de Clofazimina, em doses supervisionadas, uma vez por mês, durante dois anos ou até o paciente se tornar negativo (Tabela II). Os casos que se negassem a tomar a Clofazimina, devido à coloração que provoca, ou que fossem intolerantes a ela, deveriam receber Etionamida, na dose de $250 \mathrm{mg} / \mathrm{dia}$, sem supervisão ${ }^{12,13}$. 
Tabela II - Esquemas terapêuticos para a Hanseníase

\begin{tabular}{llcc}
\hline \multicolumn{1}{c}{ Formas da doença } & \multicolumn{1}{c}{ Drogas } & Supervisão & Duração do tratamento \\
\hline Indeterminada ou tuberculóide & Dapsona $100 \mathrm{mg} / \mathrm{d}$ & Não & 6 meses \\
& Rifampicina $600 \mathrm{mg} / \mathrm{mês}$ & Sim & \\
Dimorfa ou virchoviana & Dapsona $100 \mathrm{mg} / \mathrm{d}+$ & Não & 2 anos \\
& Clofazimina $50 \mathrm{mg} / \mathrm{d}$ & Não & \\
& Rifampicina $600 \mathrm{mg} / \mathrm{mês}+$ & Sim & \\
& Clofazimina $300 \mathrm{mg} / \mathrm{mês}$ & Sim & \\
\hline
\end{tabular}

Qual a razão desses esquemas e por que eles devem ser administrados dessa maneira? (Tabela III).

Tabela III - Vantagens dos esquemas de poliquimioterapia para a Hanseníase

- Evitar a resistência medicamentosa

- Reduzir a duração do tratamento

- Reduzir os custos do tratamento

- Aumentar a adesão do paciente

- Aumentar a motivação das equipes de saúde

- Aumentar o contato com os pacientes e a prevenção de incapacidades

Em primeiro lugar, o intuito da OMS foi evitar o aparecimento da resistência medicamentosa. Em grandes populações de bactérias, como as que apresentam os virchovianos, há subpopulações de germes mutantes, já resistentes a qualquer uma das drogas empregadas nos esquemas terapêuticos. Há uma subpopulação já resistente à Sulfona, uma outra resistente à Rifampicina e assim por diante. Pelo fato de a Rifampicina ser uma droga dotada de alto poder bactericida e verificado, experimentalmente, ser capaz de destruir, com uma única dose de $1200 \mathrm{mg}$, 99,9\% das bactérias existentes em uma amostra, ela elimina todas as subpopulações de $M$. leprae, resistentes às demais drogas. Sobra então a subpopulação resistente a ela mesma, a qual deverá ser destruída pela Sulfona e Clofazimina no esquema para MB. Estas últimas drogas, contudo, são apenas bacteriostáticas e, por isso, o tratamento deve se prolongar mais ${ }^{6}$. Nos pacientes $\mathrm{PB}$, praticamente não deve haver germes mutantes, porque a população de bacilos é muito pequena, mas, a Rifampicina tem que ser associada à
Sulfona, porque pode haver a possibilidade de resistência primária a esta última.

Um segundo motivo para a utilização dos esquemas poliquimioterápicos (PQT) é o econômico. A Rifampicina é uma droga cara e podendo ser administrada uma vez por mês, com os mesmos efeitos de quando é utilizada diariamente, fato comprovado em uma série de experiências multicêntricas, os custos com o tratamento diminuem bastante. Da mesma forma, a duração fixa do esquema para PB e a proposta de fixar em dois anos o tratamento dos casos MB alcançam o mesmo objetivo.

Outra vantagem da PQT é que, oferecendo aos pacientes uma data para a suspensão do tratamento, aumenta a sua cooperação para com o mesmo. Tratamentos muito prolongados e sem perspectivas de serem suspensos definitivamente, como ocorria com a Sulfona usada como monoterapia, fazia com que os pacientes cedo os abandonassem ou o fizessem regularmente.

Por outro lado, as doses supervisionadas mensais exigiriam um retreinamento e motivação das equipes de saúde que poderiam, então, realizar, com mais regularidade, ações de prevenção de incapacidades, e ter um maior contato com o paciente. Com isso, além de garantir a tomada dos medicamentos, poderiam aumentar a confiança do paciente e a sua adesão ao tratamento.

Hoje, o esquema alternativo, empregando a Etionamida, não é mais recomendado pela OMS, porque essa droga é muito tóxica e aumenta a sua toxicidade hepática, quando associada à Rifampicina.

Apesar disso, há um outro esquema multidroga, proposto por Freerksen et al. de Borstel, na Alemanha, que compreende o Isoprodian (Isoniazida+ Protionamida + Sulfona) associado à Rifampicina. Esse esquema terapêutico, utilizado para erradicação 
da doença na ilha de Malta, e também no Paraguai e Tanzânia, não causou sérios efeitos colaterais, segundo os seus promotores ${ }^{14}$.

\section{REAÇÕES IMUNOLÓGICAS}

Com o tratamento, a destruição dos bacilos libera antígenos que estimulam a produção de anticorpos e formam imunocomplexos que fixam complemento. Há, então, migração de neutrófilos que, com suas enzimas, provocam destruição tecidual e, muitas vezes, também a parede dos vasos. Isto se traduz, clinicamente, por alterações do estado geral, aparecimento de nódulos eritematosos e dolorosos na pele, que podem se ulcerar, e, nos surtos mais intensos, também por artrites, neurites, orquites, orquiepididimites, iridociclites, e aumento doloroso de linfonodos, do fígado e do baço (Tabela IV). Todos os locais onde há bacilos, participam do processo, inclusive aqueles sem bactérias, como é o caso do rim, em que há depósito de imunocomplexos ao nível de membrana basal de glomérulos. Esse fenômeno imunológico caracteriza o que se convencionou chamar de eritema nodoso hansênico. Essas manifestações agudas podem apresentar intensidades variáveis e ocorrem periodicamente ou esporadicamente. Há casos em que os surtos são tão freqüentes, que se tornam subentrantes, e o indivíduo entra em um estado conside-

Tabela IV - Manifestações clínicas e evolução do eritema nodoso hansênico

- Clínica:
- Queda do estado geral
- Nódulos cutâneos eritematosos
e dolorosos
- Artrite
- Neurite
- Orquiepididimite
- Iridociclite
- Adenomegalia
- Hepatosplenomegalia
- Nefrite
- Evolução:
- Surtos subentrantes: estado
de mal reacional
- Incapacidades; osteoarticulares,
oculares, neuromusculares

rado como "mal reacional". Esses episódios, principalmente aqueles mais intensos, podem causar incapacidades conseqüentes às lesões oculares, neurológicas ou do sistema osteoarticulomuscular da mão ("mão reacional"), e somente deixam de ocorrer, quando todos os antígenos são eliminados.

Admite-se, hoje, que o tratamento destrói a maior parte dos bacilos logo no seu início e, após dois anos, nos pacientes MB, todos já estão mortos. Contudo, os restos bacilares, cuja eliminação depende da imunidade celular que está deprimida ou ausente nos pacientes MB, vão desaparecendo só muito lentamente, e, enquanto estiverem presentes, há o risco da ocorrência do eritema nodoso hansênico $(\mathrm{ENH})$ e, conseqüentemente, da instalação de incapacidades. Desse modo, os pacientes não necessitam mais tratamento específico após dois anos, como comprovam estudos realizados em alguns países, inclusive no Brasil. Após a interrupção da terapêutica, os bacilos, ainda presentes, vão progressivamente sendo eliminados, até desaparecerem por completo, mas muitos doentes continuam necessitando de atenção para suas incapacidades já existentes ou para as reações (ENH) que podem continuar a ocorrer. Neste último caso, eles deixam de ter uma doença bacteriana para continuar sofrendo de uma doença imunológica.

\section{PERSPECTIVAS TERAPÊUTICAS}

A PQT é o melhor esquema terapêutico de que se dispõe no momento contra a Hanseníase. Depois de 13 anos de utilização, a taxa de recidivas tem sido extremamente baixa, cerca de $0,72 \%$ para os pacientes MB e de 1,07\% para os $\mathrm{PB}^{15}$. Por isso, na Assembléia Mundial da Saúde, realizada em 1993, os países membros se comprometeram a atingir a meta da eliminação da Hanseníase no mundo, como problema de saúde pública, no ano 2000, isto é, reduzi-la a uma taxa de 1 doente para cada 10.000 habitantes ${ }^{16}$.

O esquema multidroga é constituído por somente uma droga bactericida, que é a Rifampicina, e pelas drogas Sulfona e a Clofazimina, que são bacteriostáticas. Seria muito importante que se pudesse contar com um esquema em que todas as drogas que o constituem sejam bactericidas, e com atividade comparável à da Rifampicina.

Já estão sendo ensaiadas várias drogas bactericidas no tratamento da Hanseníase, que, provavelmente, irão fazer parte dos futuros esquemas terapêuticos. 
São elas as Fluorquinolonas (Pefloxacin, Ofloxacin e Spafloxacin), a Minociclina, a Claritromicina e o Ácido fusídico ${ }^{17 / 20}$. Comparadas com a Rifampicina, em dose única (1200 mg) experimental, o Ofloxacin atinge os mesmos efeitos, após um mês de uma dose diária, de $400 \mathrm{mg}$, e a Claritromicina e a Minociclina, após as doses diárias, respectivamente de $500 \mathrm{mg}$ e $100 \mathrm{mg}$.

Com esquemas totalmente bactericidas, porém, pode-se diminuir o tempo do tratamento específico, mas continuará persistindo a necessidade de cuidar dos pacientes, até que todos os bacilos mortos sejam eliminados.

Quanto às vacinas, existem várias delas que estão sendo experimentadas no mundo, o BCG, o BCG associado ao M. leprae morto pelo calor ou a outras microbactérias, tais como o Mycobacterium w. e o bacilo ICRC (Indian Câncer Research Council), mas ainda é muito cedo para uma conclusão definitiva quanto aos seus efeitos.

OPROMOLLA DVA. Leprosy therapeutics. Medicina, Ribeirão Preto, 30: 345-350, july/sept. 1997.

ABSTRACT: In this review, we discuss adverse effects of chemotherapeutic agents employed to treat leprosy, the evolution of treated leprotic lesions, mono- and multi- chemotherapeutic regimens, immunologic reactions caused try treatment and, finally, future prospectives of utilization of new drugs and vaccines against leprosy.

UNITERMS: Leprosy. Drug Therapy, Combination. Therapeutics.

\section{REFERÊNCIAS BIBLIOGRÁFICAS}

1 - SKINSNES OK. Origin of Chalmoogra Oil - Another version. Int J Lepr 40: 172-173, 1972.

2 - LIMA LS. Estado atual da terapêutica da lepra. Ministério da Educação e Saúde, São Paulo, 1953.

3 - KROMANN NP; WILHIELMSEN R \& STAHL D. The Dapsone syndrome. Arch Dermatol 118: 531-532, 1982.

4 - ARBISER JL \& MOSCHELLA SL. Clofazimine: A review of its medical uses and mechanisms of action. J Am Acad Dermatol 32: 241-247, 1995.

5 - GIRLING DJ. Adeverse reactions to rifampicin in antituberculosis regimens. J Antimicrob Chemoter 3: 115-132, 1977.

6 - GROSSET JH. Recent developments in the field of multidrug therapy and future research in chemoterapy of leprosy. Lepr Rev 57: 223-234, 1987. Suppl 3.

7 - LIMA LS \& ARANTES FR. Resistência do Bacilo de Hansen a quimioterapia. In: Anais, VIII Congresso Internacional de Leprologia, Rio de Janeiro, p. 414-437, set. 1963.

8 - PETTIT JHS; REES RJ \& RIDDLEY DS. Studies on sulfone resistance in leprosy. Int J Lepr 35: 373-390, 1966.

9 - JACOBSON RR \& HASTINGS RC. Rifampicin resistance in leprosy. Lancet 2: 1304-1305, 1976.

10 - ORGANIZAÇÃO MUNDIAL DA SAÚDE. Quinto Informe: Comité de Expertos de la OMS en la Lepra. Genebra. Sér Inf Técn 607, 1977. 51 p.

11 - ORGANIZAÇÃO MUNDIAL DA SAÚDE. Quimioterapia da hanseníase para Programas de Controle: Relatório de um Grupo de Estudos. Sér Infor Técn 607, 1982. 24 p.
12 - OPROMOLLA DVA. Terapêutica multidroga. An Bras Dermatol 65: 37-40, 1990.

13 - ROLLIER R \& ROLLIER MT. Traitement de la lèpre par l'ethionamide. Maroc Med 52: 148-166, 1972.

14 - ALVARENGA AE. Report of the Joint Leprosy - Tuberculosis: Project in Paraguay. In: Symposium on Multidrug Therapy in Leprosy. Wurzburg. 1986. Lepr Rev 57: 53-59 1986 Suppl 3.

15 - CHEMOTERAPY OF LEPROSY. Report of a WHO Study Group. WHO Tech Rep Ser 847, 1994.

16 - NOORDEEN SK. Elimination of leprosy as a Public Health problem. Int J Lepr 62: 278-283, 1994.

17 - FAJARDO TRANQUILINO Jr. T et al. Minocycline in lepromatous leprosy. Int J Lepr 63: 8-17, 1995.

18 - BAOHONG Jl et al. Powerful bactericidal activities of clarithromycin and minocycline against Mycobacterium leprae in the treatment of lepromatous leprosy $\mathbf{J}$ Infect Dis 168: 188-190, 1993.

19 - MC DERMOTT-LANCASTER RD \& BANERJEE DK. Activity of sparfloxacin against mycobacterium leprae measured by the proportional bactericidal test. Int J Lep 61: 605-608, 1993.

20 - GROSSET JH et al. Clinical trial of Pefloxacin and Ofloxacin the treatment of lepromatous leprosy. Int J Lep 58: 281-295, 1990.

Recebido para publicação em 02/07/97

Aprovado para publicação em 30/07/97 